\title{
Directed organ donation after medical assistance in dying: little to gain and much to lose
}

\author{
Claire Middleton, MD, FRCPC
}

Received: 7 April 2020/Accepted: 7 April 2020/Published online: 30 April 2020

(C) Canadian Anesthesiologists' Society 2020

\section{To the Editor,}

While applauding the willingness of Casey et al. ${ }^{1}$ to present their ideas concerning directed donation in the context of medical assistance in dying (MAiD), I fundamentally disagree with their main conclusion that, despite the recommendations from the recent guidelines for policy, "real world" considerations compel us to be open to the concept of a patient who is contemplating MAiD being able to select the recipient of their organ(s) after death. The transplant community has little to gain and much to lose if it endorses directed donation after MAiD.

Why so little to gain? Because the yield of organs is likely to be very small. Using the authors' own figures, among the 6,749 cases of MAiD over the reporting period, only 56 patients in our three most populous provinces (Ontario, British Columbia, Quebec) requested assessment for donation and only 30 actually donated (presumably mostly non-directed) over a similar period. This is not surprising. Indeed, most MAiD patients are medically unsuitable to donate, many find the additional testing burdensome, and most choose to die at home, all of which precludes donation. In Ontario, patients approved for MAiD are formally approached for donation if medically suitable, so there is no lack of awareness about the potential to donate.

Why so much to lose? Because, as the authors recognize, it is essential to "maintain public trust and

Editor's Note: The authors of the article: Can J Anesth 2020; https:// doi.org/10.1007/s12630-020-01632-5, respectfully declined an invitation to submit a reply to the above letter.

C. Middleton, MD, FRCPC ( $\square)$.

University of Toronto, Toronto, ON, Canada

e-mail: claire.middleton@uhn.ca integrity" in the system. I argue that this could be severely compromised if we condone the acceptance of donated organs where coercion is a real possibility. European experience with euthanasia has shown that "the decision is not straightforward; sometimes people change their minds right up to the end." 3 In the referenced article by Rosenbaum, ${ }^{4}$ an Ontario anesthesiologist discusses a patient who decided that she did still want to live after requesting MAiD but "was afraid to admit it in front of her family". He has witnessed such a change of mind four times and "acknowledges the added risk of external pressure for organ donation: people with second thoughts may feel, 'I'd better do this because people are waiting for my organs." While we do not have a denominator for added context, it is significant that he is aware of four cases in his practice. Therefore, since patients contemplating MAiD can feel pressured to proceed without the added issue of donation, real or perceived coercion can certainly exist for those contemplating donation. The decision becomes particularly prone to "undue contamination" with directed donation in multiple ways. The timing of MAiD may become subordinated to the needs of the recipient. For example, is MAiD delayed until a sufficiently high model for end-stage liver disease score is reached, or does it get expedited because of the development of a hepatoma on a background of previously indolent viral cirrhosis? There is total loss of anonymity for the donor, and unlike living donors, they cannot revoke consent behind a screen of "medical reasons". Furthermore, we must also appreciate that coercion can exist for both donor and recipient. The recipient's belief system cannot be assumed to be congruent with that of the donor and it should be recognized that altruism can exist bilaterally. A potential 
recipient may not wish to expedite their chance of transplantation if it means the expedited death of another.

As the government contemplates extending MAiD eligibility to include non-terminal conditions, we must acknowledge that all lives are to be valued-we cannot prioritize between groups. Fears about "objectionable paternalism" do not absolve us of the responsibility to consider our decisions in the widest possible context. While there may be rare situations where directed donation after MAiD is possible, timely, and welcome, the risk of coercion in other cases is too real to allow us to endorse this path.

Conflicts of interest None.

Funding statement None.

Editorial responsibility This submission was handled by Dr. Hilary P. Grocott, Editor-in-Chief, Canadian Journal of Anesthesia.

\section{References}

1. Casey GM, Kekewich M, Naik VN, et al. A request for directed donation in medical assistance in dying (MAID). Can J Anesth 2020; DOI: https://doi.org/10.1007/s12630-020-01632-5.

2. Downar J, Shemie SD, Gillrie C, et al. Deceased organ and tissue donation after medical assistance in dying and other conscious and competent donors: guidance for policy. CMAJ 2019; 191: E60413.

3. Mulder J. Facilitating the wishes of patients who choose both MAID and organ donation. CMAJ 2019; 191: E595-6.

4. Rosenbaum L. Altruism in extremis - the evolving ethics of organ donation. N Engl J Med 2020; 382: 493-6.

Publisher's Note Springer Nature remains neutral with regard to jurisdictional claims in published maps and institutional affiliations. 